\title{
Female Copulation Calls in Guinea Baboons: Evidence for Postcopulatory Female Choice?
}

\author{
Dario Maestripieri, ${ }^{1,2}$ Marco Leoni, ${ }^{1}$ Sania S. Raza, ${ }^{1}$ \\ Elizabeth J. Hirsch, ${ }^{1}$ and Jessica C. Whitham ${ }^{1}$ \\ Received March 17, 2004; revision May 04, 2004; accepted August 12, 2004
}

\begin{abstract}
We tested the hypothesis that primate female copulation calls are a form of postcopulatory female choice. We collected data on female sexual swellings, sexual and agonistic behavior, copulation calls and postcopulatory behavioral interactions in a multimale-multifemale captive group of Guinea baboons over a 3-mo period. Males copulated with only a few females, and females copulated with only 1 or 2 different males in the group, suggesting a harem-like mating system similar to that of hamadryas and gelada baboons. Female copulations were most likely to occur at peak sexual swellings and male copulatory success was accounted for by dominance rank and age. Variation in female tendencies to call after copulation is best explained by the copulatory success of the male with which each female copulated the most and by the number of copulating partners. The findings are consistent with predictions that calls are likely to be associated with copulation with preferred males and the risk of sperm competition. The prediction that copulation calls increased the probability of postcopulatory mate guarding is also supported. Taken together, the findings suggest that female copulation calls may play an important role in postcopulatory sexual selection and in particular in the expression of postcopulatory female choice in primate species in which females have little opportunity to choose their mates or female mate choice is costly or both.
\end{abstract}

KEY WORDS: copulation calls; postcopulatory female choice; mate guarding; Baboons.

\footnotetext{
${ }^{1}$ Animal Behavior Research Group, The University of Chicago, 5730 S. Woodlawn Avenue, Chicago, Illinois 60637, USA.

${ }^{2}$ To whom correspondence should be addressed; e-mail: dario@uchicago.edu.
} 


\section{INTRODUCTION}

In baboons (Papio spp.) and some other species of Old World monkeys and apes, females often give low-pitched rhythmic vocalizationscopulation calls-during and following copulation (Dixson, 1998). The function of copulation calls is not entirely clear, though their timing of occurrence relative to copulation, i.e. the fact that they typically begin in the last stage of the mount and continue after copulation, suggests that they may play a role in postcopulatory sexual selection. Postcopulatory sexual selection operates via 2 mechanisms: sperm competition and postcopulatory female choice (Birkhead and Pizzari, 2002). Thus, one possibility is that female copulation calls serve to incite mating with multiple males and stimulate sperm competition, confuse paternity, and reduce the risk of infanticide (Hamilton and Arrowood, 1978; O'Connell and Cowlishaw, 1994; Semple, 1998). Another possibility is that copulation calls represent a form of postcopulatory female choice, whereby females use them selectively with high-quality males or males with a compatible genotype to encourage mate guarding, prevent sperm competition, and maximize the probability of fertilization (Maestripieri and Roney, 2005). According to this female-choice hypothesis, copulation calls inform the copulating male that the female is fertile and that there is a high probability that the copulation will lead to fertilization. The sperm competition/paternity confusion hypothesis and the female-choice hypothesis therefore postulate opposite functions for copulation calls. In one case, they are expected to maximize the likelihood of mating with multiple partners and the occurrence of sperm competition; in the other, they are expected to increase mate guarding and minimize the likelihood of mating with multiple partners and the occurrence of sperm competition. The 2 hypotheses also lead to a number of different empirical predictions.

We aimed to test the female-choice hypothesis of female copulation calls in Guinea baboons (Papio papio). Female copulation calls have been reported in them (Boese, 1975; Byrne, 1981) and in other species of Papio: P. cynocephalus (Semple, 2001), P. anubis (Saayman, 1970), P. ursinus; (Hamilton and Arrowood, 1978), P. hamadryas (Swedell and Saunders, 2003) and as well as Theropithecus gelada (Aich et al., 1990; Moos-Heilen and Sossinka, 1990).

Baboons generally meet the conditions for postcopulatory sexual selection. In all species, there is marked sexual dimorphism in body size and males compete for access to females. Yellow, olive, and chacma baboonscollectively savanna baboons-live in multimale-multifemale social groups and engage in promiscuous mating (Melnick and Pearl, 1987). Hamadryas and gelada baboons live in small units (harems) comprising one dominant 
male (harem leader), usually one subordinate male (follower), and several females and their offspring (Stammbach, 1987). The small units congregate into larger units (troops) for sleeping and occasionally also travel and forage together. Females typically mate with the male(s) in their harem, but extraharem copulations have been observed or are possible in both hamadryas and gelada baboons (Dunbar and Dunbar, 1975; Kummer, 1968). Guinea baboons are the least studied of the 6 species of baboons. Early studies suggested that Guinea baboons are characterized by a social organization intermediate between that of savanna baboons and those of hamadryas and gelada baboons. In particular, like savanna baboons, Guinea baboons live in large multimale-multifemale troops of 50-300 individuals (Anderson and McGrew, 1984; Bert et al., 1967; Byrne 1981; Dunbar and Nathan, 1972). However, like hamadryas and gelada baboons, the troops are subdivided into small units consisting of 1 or 2 males and 2-5 females and their offspring (Boese, 1975; De Keyser, 1956, in Boese, 1975; Dunbar and Nathan, 1972). Furthermore, in captive social groups, male Guinea baboons maintain harems of 2-5 females with which they mate and affiliate. The harems may contain 1 or 2 males (Boese, 1975).

The occurrence of sperm competition in baboons is suggested by several characteristics: males have high ejaculation rates and relatively large testicular size relative to body mass (Bercovitch, 1989; Harcourt, 1981); males engage in mate guarding following copulation (Manson, 1997); females in all baboon species advertise fertility with exaggerated sexual swellings, a trait that across all primate species is generally associated with mating or sperm competition (Dixson, 1983, 1998). Comparative data on testicular size, ejaculation rates, and mate guarding suggest that sperm competition is intense in yellow and olive baboons and lower in hamadryas and gelada baboons (Bercovitch, 1989; Jolly and Phillips-Conroy, 2003). Cowlishaw and O'Connell (1996) and Henzi (1996) provided contrasting views of sperm competition in chacma baboons. Little is known about Guinea baboons. However, even in species that do not live in multimalemultifemale groups, the potential for postcopulatory sexual selection exists as long as females have the opportunity to mate with 2 different males in their social unit. Moreover, there are frequent male takeovers (Stammbach, 1987), and it is possible that copulation calls may promote mating with multiple males, confuse paternity, and reduce the risk of infanticide that is associated with male immigration and takeover (Cowlishaw and O'Connell, 1996; Zinner and Deschner, 2000).

All species of baboons, and especially the 3 species of savanna baboons, engage in mate guarding following copulation. The primary function of mate guarding is to prevent sperm competition (Birkhead and Pizzari, 2002). Although the exact mechanisms of sperm competition in 
primates are not known (Gomendio et al., 1998), for the purposes of the female-choice hypothesis of copulation calls, this is not a problem as long as it can be demonstrated that there is potential for sperm competition and that mate guarding occurs. In a study of Barbary macaques (Macaca sylvanus) Todt et al. (1995) reported that after copulations accompanied by calls, males were more likely to remain in proximity to the female than after copulations not accompanied by calls. This finding supports one of the predictions of the female-choice hypothesis. However, the key prediction of the female-choice hypothesis that females encourage mateguarding by preferred males but not by nonpreferred males has not been tested.

We described the patterns of copulation in a group of Guinea baboons, investigated the possible determinants of variability in female and male copulatory success, and tested the following predictions of the female choice hypothesis of copulation calls. Copulation calls should be most likely to occur in association with: 1) peak female fertility as expressed by maximal sexual swellings; 2 ) copulation with high quality (high-ranking or highly successful) males; and, 3) copulation with multiple males and high opportunity for sperm competition. Copulation calls should also have the following effects on behavior: 1) the consort males should be less likely to leave the females and more likely to spend time in proximity to them; 2) the calling females should show no active interest in mating with other males; and, 3) calling females should be less likely to mate with other males than non-calling females. These predictions are contrasted to those of the sperm competition/paternity confusion hypothesis of copulation calls, according to which 1) females that mate with subordinate or subadult males should be more likely to call than females that mate with adult dominant males, 2) females that typically mate with one or few males should be more likely to call than females that mate with multiple males because in the former case there is greater need to encourage sperm competition and paternity confusion, and 3) all females should actively solicit copulation from males other than their consort partners.

\section{METHODS}

\section{Subjects and Housing}

We studied a group of Guinea baboons at Brookfield Zoo in Brookfield, IL. The group is housed in an outdoor, multilevel, grotto comprised of artificial rocks and measuring $57.3 \mathrm{~m} \times 47.2 \mathrm{~m}$. The baboons also have access to an indoor holding and feeding facility, in which they have 
an unlimited supply of water and monkey chow. At $c a .1100 \mathrm{~h}$ each day, the group receives a combination of various fruits and vegetables. At the beginning of the study, the group comprised 15 adult males (age range: 9-22 yr; mean $\pm \mathrm{SD}=14 \pm 4.2$ ) and 25 adult females (age range: $11-21 \mathrm{yr}$; mean \pm $\mathrm{SD}=14.4 \pm 2.9$ ). There were no infants, juveniles, or subadults. All adult males were vasectomized and one was castrated, while all females except one were intact and cycling. Two intact females died early in the study and were excluded from subsequent analyses.

We collected data ad libitum on dyadic aggression, submission, and spatial displacements and combined them with data from previous studies to establish a dominance hierarchy. We entered the data into a matrix and ranked individuals so as to minimize the number of reversals on one side of the diagonal. Although 5 top-ranking and 5 bottom-ranking males were clearly identified, there were not enough observations to rank all 15 males in a linear order. Therefore, for analysis we subdivided the males into 3 categories of dominance rank $(n=5)$, high, middle and low. There was not enough information to establish a dominance hierarchy for the females; therefore, female dominance rank is not included as a variable in the study.

\section{Swelling Data}

We recorded data on female sexual swellings once per day, Monday through Friday, for a total of 63 days. Occasionally a few females were missed or were absent from the group due to illness. We assigned swelling size scores from 1 to 3 , with 1 being smallest and 3 largest. We used swellings size 3 to indicate periovulatory periods within the menstrual cycle (Shaik et al., 1982; Gauthier, 1999). All females, except one, showed variation in swelling size over time, and we took interindividual variation in swelling sizes into account when scoring it. Swelling size score assignments for all females involved in sexual activity were re-checked and confirmed by 2 independent observers from videotapes of postcopulatory behavior.

\section{Behavioral Data}

Two observers collected behavioral data 5-10 h per day, 5 days a week for $c a$. 3 mo via a digital camcorder, an audio tape-recorder, and binoculars. Whenever we observed a heterosexual copulation involving male intromission and pelvic thrusting, we videotaped the female's behavior for 10 min following the copulation. We also videotaped the copulating male's behavior following copulation. If the copulating male went out of sight, an observer followed the focal female. We used the audio tape-recorder 
to verbally record whether or not the copulation was accompanied by a copulation call. In some cases, copulation calls were also clearly audible in the videotapes. We also made observations ad libitum of any sexual activity in the group and of any episode of aggression or submission involving any group member. Two observers were at opposite ends of the enclosure to monitor all the individuals within the group at all times.

Videotapes were later coded for behavior by two observers, via a digital VCR and playing the tape in slow motion or frame-by-frame, whenever necessary. We recorded data with the focal sampling technique and included interactions between the focal female and the copulating male, between the focal female and other group members, and between the copulating male and other group members. We recorded the amount of time spent in proximity within arms reach and the amount of time spent allogrooming. We also recorded frequency of the following behaviors: approaches and leaves, initiation and termination of grooming, grooming solicitations, aggression (threats, attacks and chases), submission (fear grin) and spatial displacements, sexual presentations, noncopulatory mounts, i.e, mounts not involving intromission and pelvic thrusting, and copulations, i.e., mounts involving intromission and pelvic thrusting, lip-smacking, vocalizations, and displays, e.g., branch-shaking or jumping. We analyzed data and present them as frequencies and durations of behavior per $10 \mathrm{~min}$ of observation.

\section{Statistical Analyses}

We analyzed data via Pearson's and Spearman correlation tests (all correlations involved the Pearson's test, unless otherwise noted), linear and multiple regression, chi-quare tests, Student's $t$ tests, and analyses of variance (ANOVA) followed by Bonferroni-Dunn tests post hoc. Whenever the data were non-normally distributed or the variances were non-homogeneous, we log transformed the data. All tests are 2 tailed and probabilities $\leq 0.05$ are statistically significant.

\section{RESULTS}

\section{Female Sexual Swellings}

After the exclusion of the 2 females that died early in the study, swelling data are available for 23 females for an average of 59.7 days $(\mathrm{SEM}=0.73$; range 51-63). The ovariectomized female always received a swelling score of 1 and did not copulate, therefore she was excluded from subsequent analyses. The remaining 22 females had an 
average of $3.00( \pm 0.11)$ periovulatory periods. Specifically, 16 females had 3 periovulatory periods, 3 females had 2 periovulatory periods, and 3 females had 4 periovulatory periods. There was considerable variability among females in the number of days spent in each swelling size stage. The daily average swelling size score ranged from 1.47 to 2.38 (mean $\pm \mathrm{SEM}=$ $1.81 \pm 0.06)$. In particular, the number of consecutive days in which a female had a swelling score of 3 ranged from 3 to 9.67 (5.33 \pm 0.40$)$. Differences in the number of periovulatory periods $(2,3$, or 4$)$ during the study period did not account for variation among females in daily average swelling size score (factorial ANOVA, F 2,21 $=2.2$, ns) or in duration of full swelling periods $(\mathrm{F} 2,21=0.25, \mathrm{~ns})$, suggesting that variation in swelling size among females is not the by-product of a sampling bias. The daily average swelling size scores and the duration of full swelling periods are highly positively correlated $(r=0.88, p<0.0001)$. Female age is a significant predictor of daily average swelling size (F 1,21 $=9.37, r 2=0.32, p<0.01)$, with older females having higher swelling scores than those of younger females. However, if the oldest female ( $22 \mathrm{yr}$ ) is excluded from the analysis, the regression is no longer significant, suggesting that it is mostly due to her. Age is not a significant predictor of the duration of full swelling periods.

\section{Copulations and Female Swellings}

Of the 22 females that showed changes in swelling size, 21 copulated $\geq 1$ time (total $n=123$ ). Among the copulating females, the number of copulations per female ranged from 1 to $15(5.86 \pm 0.99)$. Variation among females in the number of copulations is not accounted for by age, daily average swelling size, duration of full swelling periods, or number of periovulatory periods. Number of copulations is significantly different in relation to swelling size score (repeated measures ANOVA, F 2,62 $=12.22$, $p<0.0001$ ), with copulations being significantly more likely to be associated with swelling size 3 than with size $2(p<0.05)$ or size $1(p<0.05$; Fig. 1). There is no significant difference in the number of copulations between swelling sizes 2 and 1 .

Each female copulated with only a few males. Specifically, 13 females copulated with only 1 male, 7 females copulated with 2 males, and 1 female copulated with 3 different males. There is no significant difference in number of copulations among females that copulated with 1 male $(5.00 \pm 1.32)$ and females that copulated with 2 or 3 males $(7.25 \pm 1.42)$. The females that copulated with 2 or 3 males had significantly higher daily average swelling size $(t=-2.91 ; p<0.01 ;$ Fig. $2 \mathrm{a})$ and significantly longer periods of time in full swelling than the females that copulated with 1 male did $(t=-2.91$; 


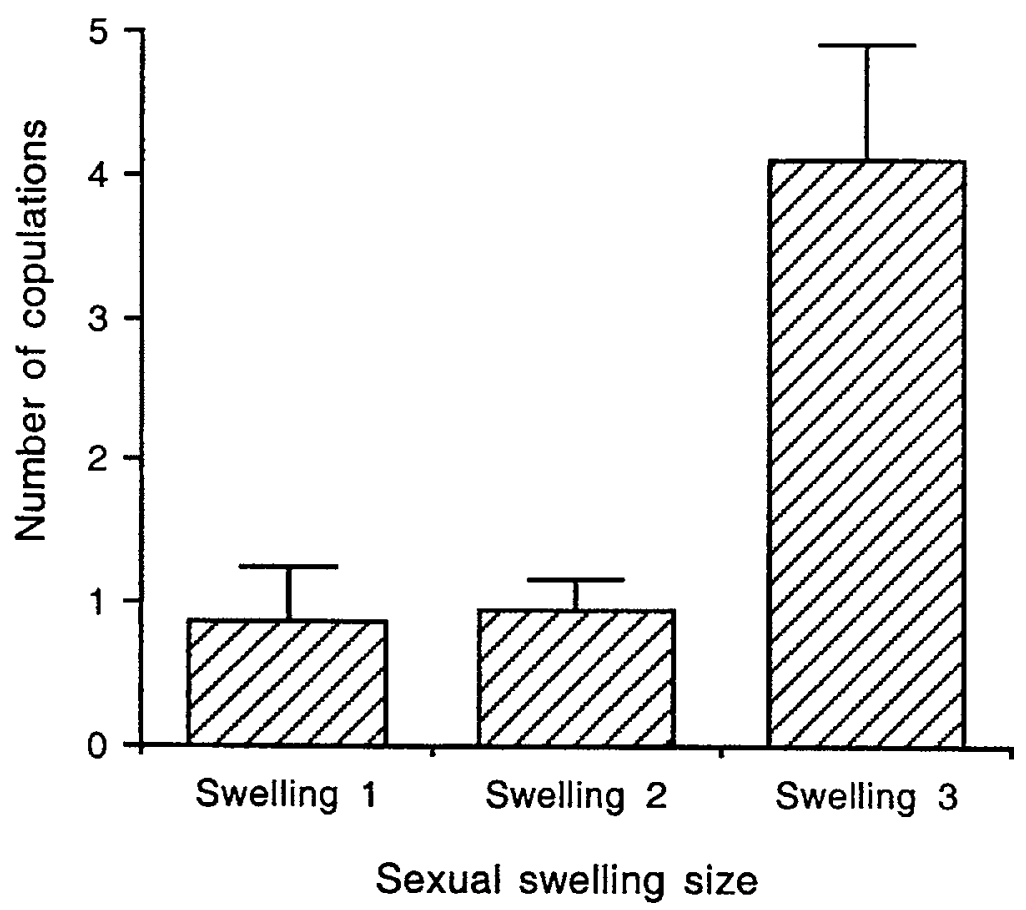

Fig. 1. Mean $( \pm S E M)$ number of copulations per female in relation to the size of her sexual swelling.

$p<0.01$; Fig. 2b). There is no significant difference in female age or in the number of periovulatory periods in relation to number of copulating partners.

\section{Male Rank, Age, and Copulatory Success}

Of the 15 adult males in the group, 9 copulated. Among them, the number of copulations per male ranged from 1 to 40 (13.3 \pm 4.1$)$. Male rank had a statistically significant effect on copulatory success $(\mathrm{F} 2,13=7$, $p=0.01)$, with high-ranking males ( $20 \pm 5.7$ copulations) being more successful than both middle $(4.4 \pm 2.4$ copulations; $p<0.05)$ and low ranking males ( 0 copulations; $p<0.05$ ). All of the 5 high-ranking males and 4 of the 5 middle-ranking males copulated, whereas none of the 5 low-ranking males did. There is no significant difference in copulatory success between middle- and low-ranking males. Since one of the low-ranking males (the oldest male in the group) was castrated, we excluded him from subsequent analyses. 

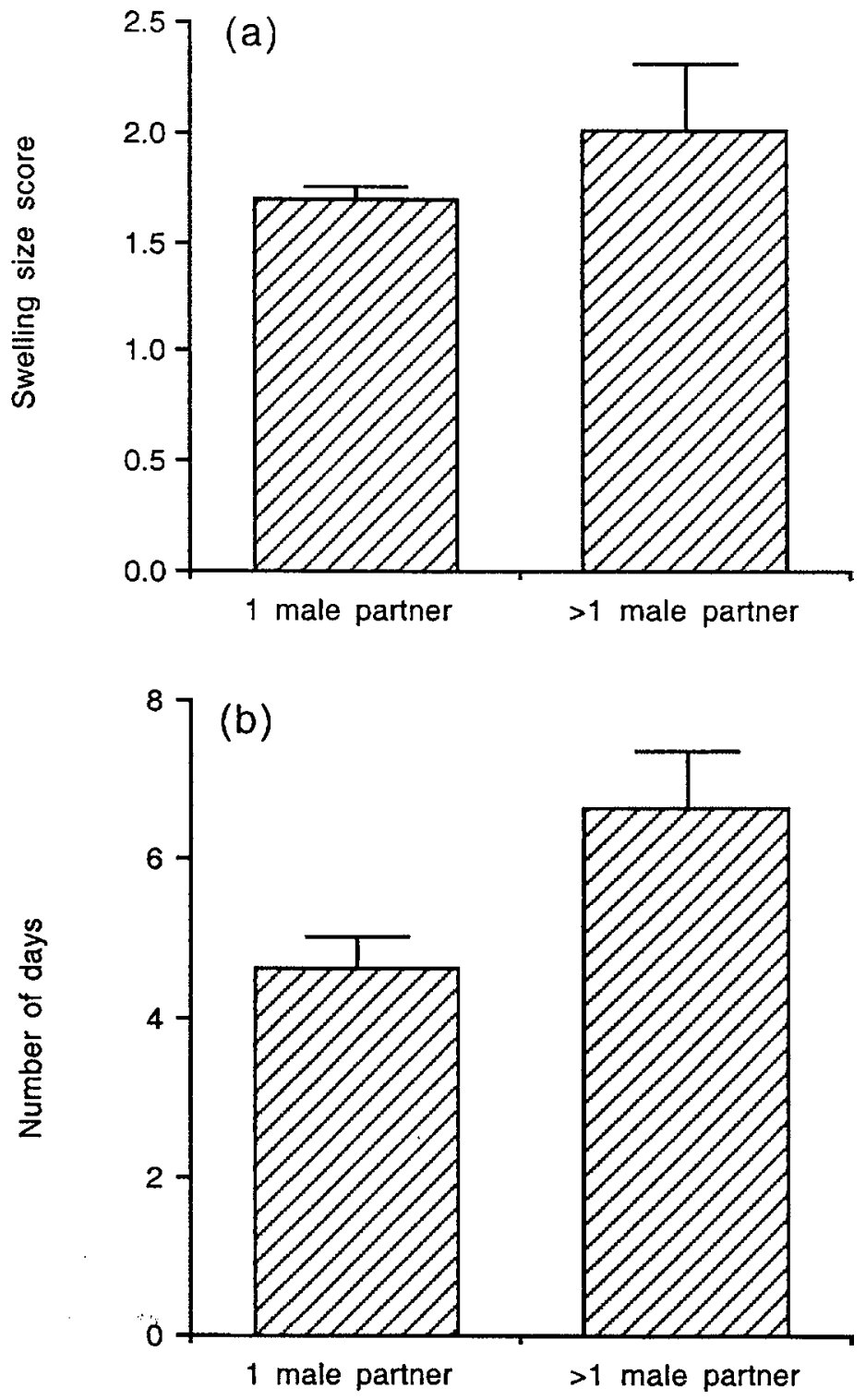

Fig. 2. (a). Mean ( \pm SEM) daily average sexual swelling score per individual in females that copulated with only 1 male, or with 2 or 3 males. (b). Mean $( \pm$ SEM) duration of periods of full sexual swelling (score 3 ) per individual in females that copulated with only 1 male, or with 2 or 3 males. 
Male copulatory success is negatively correlated with age across the 14 males $(r=0.61, p<0.05)$ but the effect is, at least in part, mediated by rank because rank is significantly influenced by age $(\mathrm{F} 2,13=$ $7.36, p<0.01)$. In particular, high-ranking $(12 \pm 0.8 \mathrm{yr})$ and middle ranking males $(13.6 \pm 0.8 \mathrm{yr})$ were significantly younger than low-ranking males $(18.5 \pm 2 ; p<0.05$ in both cases). The difference in age between high- and middle-ranking males is not significant. However, among the 10 high- and middle-ranking males, copulatory success is significantly negatively correlated with age $(r=0.68 ; p<0.05)$. Therefore, it seems that both rank and age are important determinants of male copulatory success.

The number of female partners for each male ranged from 1 to 5 (3.3 \pm $0.5)$. The overall number of male copulations is positively correlated with the number of partners $(r=0.67, p<0.05)$, suggesting that access to more females increased a male's copulatory success. However, when only the copulations with each male's favorite partner are considered, i.e., the female with which he copulated the most, the ranking of the males in terms of their copulatory success is identical to that obtained with the overall number of copulations, with the exception of a reversal between the second and third most successful male (Spearman correlation, $r=0.70, n=9$, $p<0.05)$. Therefore, the more successful males had both higher rates of copulation, at least with their favorite partner, and a higher number of partners than the less successful males did.

Copulations were not evenly distributed between the males that shared females. Among the 8 females that copulated with $>1$ male, $82.6 \%$ of copulations occurred with a primary male partner and $17.3 \%$ with a secondary or tertiary partner. Among all the 21 copulating females in the group, 16 copulated primarily with a high-ranking male and 5 females copulated primarily with a middle-ranking male. There is no significant difference in daily average swelling score $($ high $=1.8 \pm 0.1$; middle $=1.8 \pm 0.2$ ) or the duration of full swelling period (high $=5.5 \pm 0.4$; middle $=5.5 \pm$ 1.4) between the females that primarily copulated with a high-ranking male and the females that primarily copulated with a middle-ranking male.

Among the copulating males, high-ranking males had a higher percentage of copulations with females in swelling stage 3 (76.1 \pm 9.7$)$ than middleranking males $(54.2 \pm 21.6)$ but the difference is not statistically significant. There is no significant correlation between male age or copulatory success and percentage of copulations with females in swelling stage 3 . There are also no significant correlations between male age or copulatory success and the daily average swelling score or the duration of full swelling period of each male's favorite partner. 


\section{Copulations, Swellings, and Copulation Calls}

Sixty-one \% of copulations were followed by female copulation calls. Across all copulating females, copulations associated with swelling scores of 3 were most likely to be followed by calls and copulations associated with swelling scores of 1 were least likely to be followed by calls (chi square $=11.25$, df $=2 ; p<0.01$; Fig. 3). For 12 females, it was possible to run an intra subject analysis and assess whether they were more likely to call in swelling size 3 than in swelling size 1 or 2 , controlling for the number of copulations in the different swelling size stages. The difference is not statistically significant $(t=-1.14, \mathrm{df}=11, p=0.28)$. Specifically, 7 females were more likely to call in stage 3 than in stage 1 or $2 ; 2$ were less likely to call in stage 3 than in stage 1 or 2 ; and, for 3 females the probability was the same. Because more than half the subjects were not included in the analysis, it is possible that with a larger sample the association between larger swelling size and copulation calls would have been significant also in the intra subject analysis.

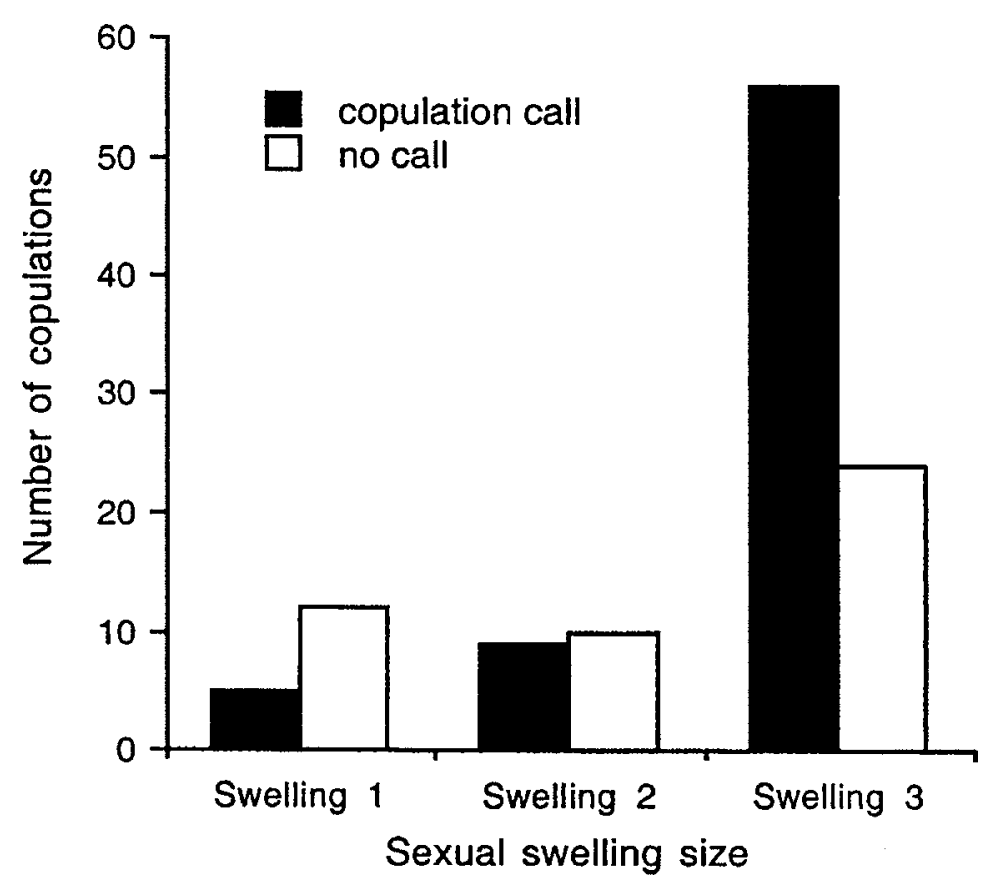

Fig. 3. Total number of copulations followed and not followed by copulation calls in relation to sexual swelling size. 
We performed a step-wise regression analysis using the percentage of female copulations followed by calls as the dependent variable and the following possible predictors: female age, the female daily average swelling score, the duration of full swelling periods, the total number of copulations per female, the percentage of female copulations occurring in swelling stage 3 , the number of male partners, and the rank, age and copulatory success of the male with which each female copulated the most. The best predictor of variation in female copulation calls was the copulatory success of the male with which each female copulated the most. Specifically, the higher the copulatory success of each female's primary partner the higher the proportion of her copulations that were followed by calls $(r 2=0.38, \mathrm{~F}=11.83, p<0.01$; Fig. $4 \mathrm{a})$. The second best predictor of variation in female copulation calls was the number of male partners ( $r 2=0.53, \mathrm{~F}=10.19, p<0.01)$. Specifically, the females that copulated with 2 or 3 males were significantly more likely to call after copulation than those that copulated with one male $(t=-2.06 ; p=0.05 ;$ Fig. $4 \mathrm{~b})$. The association between male copulatory success and female copulation calls was also confirmed with an intra subject analysis. Among the 8 females that copulated with $>1$ male, the percentage of copulations accompanied by calls was higher following copulation with more successful males (96.77 \pm 2.12) than following copulation with less successful males $(37.15 \pm 14.99$; t-test for paired samples, $t=3.83$, df $=7, p<0.01$ ).

\section{Copulation Calls, Swellings, and Postcopulation Behavior}

Behavioral data are available for 9510 -min periods following copulations. We discarded a few recordings due to the poor quality of the video. We analyzed interactions between the copulating male and female via a $2 \times 2$ factorial ANOVA, with factors being the occurrence of copulation calls and the swelling stage of the female. The analysis revealed significant main effects of copulation calls and female swelling scores on measures of proximity. Specifically, following copulations accompanied by calls, and irrespective of swelling stage, males were less likely to leave the female, $\mathrm{F}(1$, $91)=4.56, p<0.05$ (Fig. 5) than following copulations not accompanied by calls.

When females were in swelling stage 3, and irrespective of the occurrence of copulation calls, the total number of approaches between male and female and the total time spent in proximity are significantly higher than when females were in swelling stages 1 and 2 (number of approaches, stage $3=2.39 \pm 1.74$; stage $1-2=1.65 \pm 1.71 ; \mathrm{F}(1,91)=4.39, p<0.05$; time in proximity, $\mathrm{F}(1,91)=5.60, p<0.05$; Fig. $6 a)$. The difference is probably the 

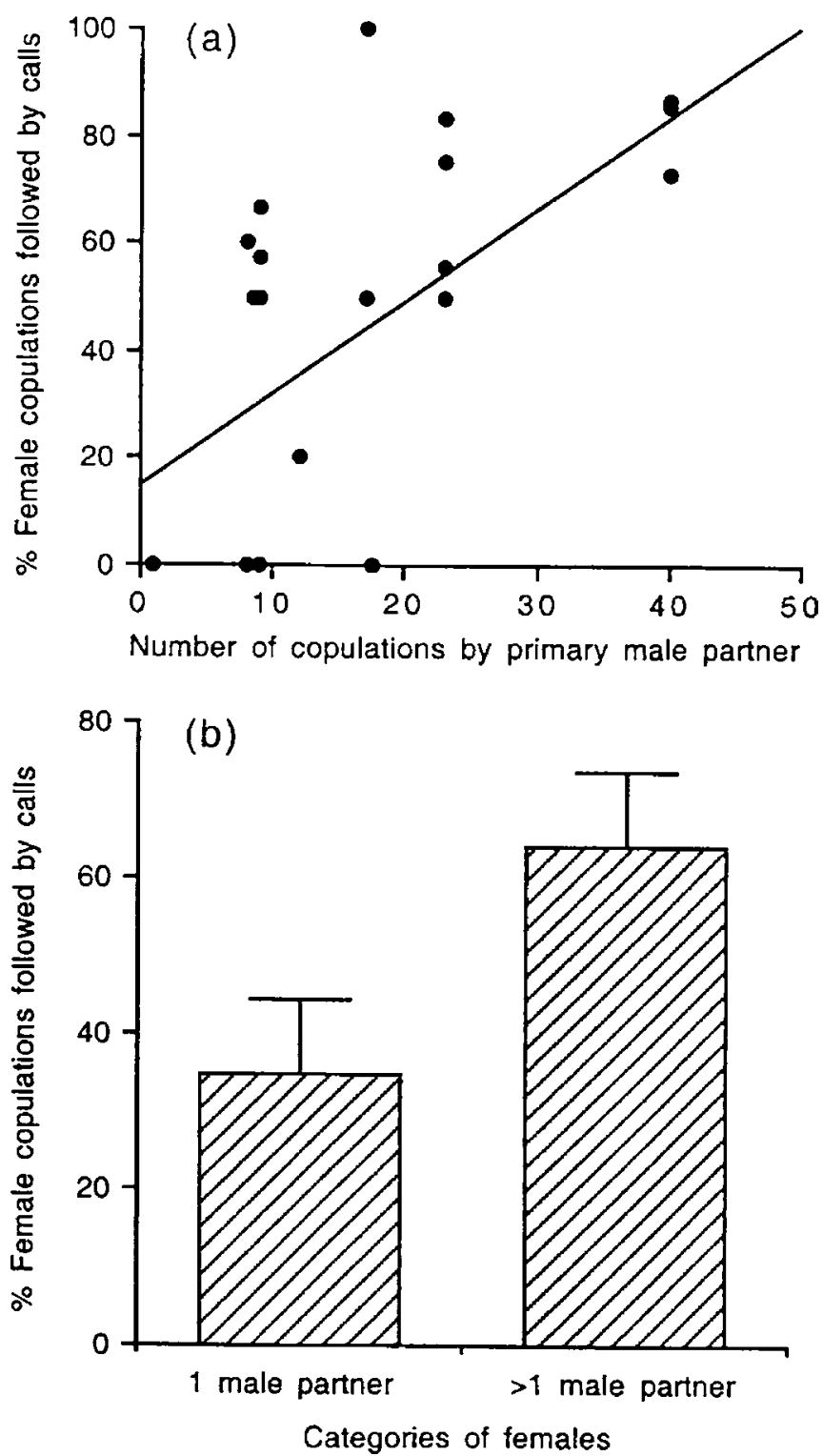

Fig. 4. (a). Regression between \% of female copulations followed by calls and number of copulations achieved by the male with which each female copulated the most. (b). Mean $( \pm$ SEM) \% of copulations followed by calls in females that copulated with only 1 male, or with 2 or 3 males. 


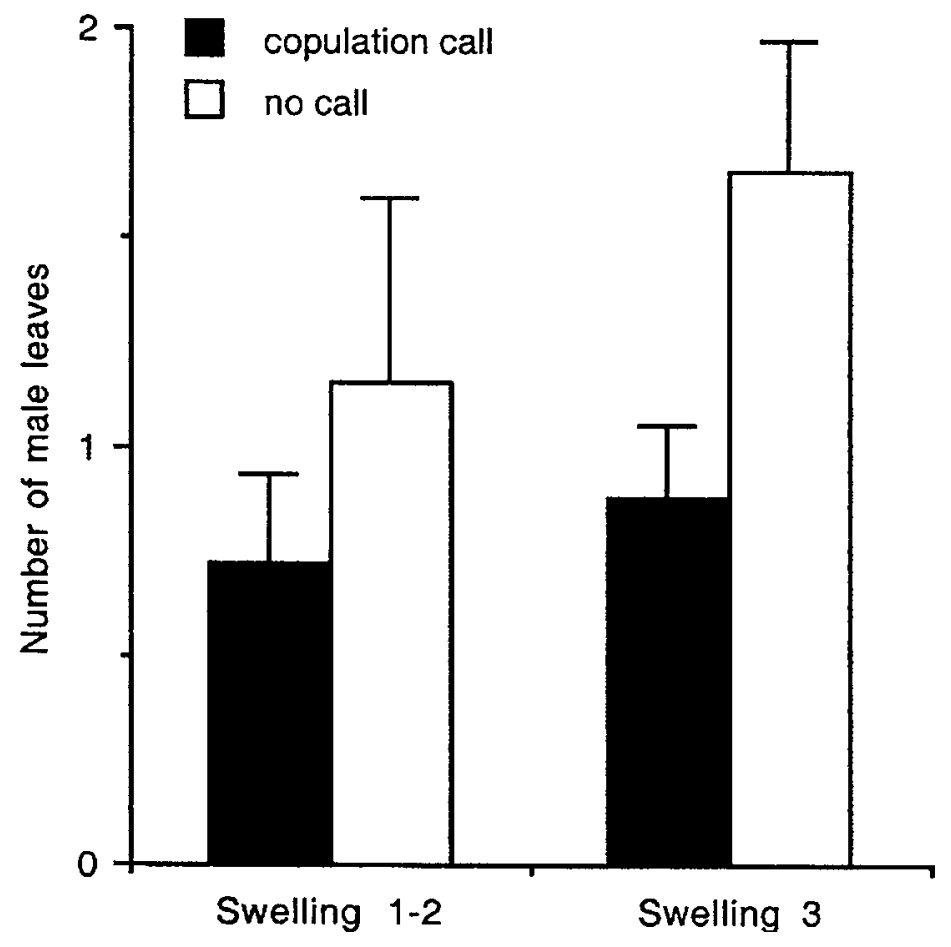

Fig. 5. Mean $( \pm S E M)$ number of times the consort male left the consort female in the 10 -min copulatory period in relation to her sexual swelling size and the presence or absence of copulation calls.

result of male behavior because they tended to follow females in swelling stages 3 more than females in stages 1 or $2, \mathrm{~F}(1,91)=3.48, p=0.06$ (Fig. $6 \mathrm{~b}$ ) and the duration of male-initiated proximity is significantly higher with females in swelling stages 3 than with females in stages 1 and $2 \mathrm{~F}(1$, $91)=5.15, p<0.05$ (Fig. 6c). There is no significant difference in the number of female approaches or the duration of female-initiated proximity in relation to swelling stage. There is no significant interaction between copulation calls and swelling scores for any male-female interaction. However, the data in Figure 6 suggest that the increase in male following and proximity duration associated with the full swelling was higher when copulation calls occurred than when they did not occur.

There is no significant difference in female behavior toward other males during the postcopulatory period in relation to the presence or absence of copulation calls. Neither the male nor the female of the pair copulated with other individuals in the 10 -min period following their copulation. 

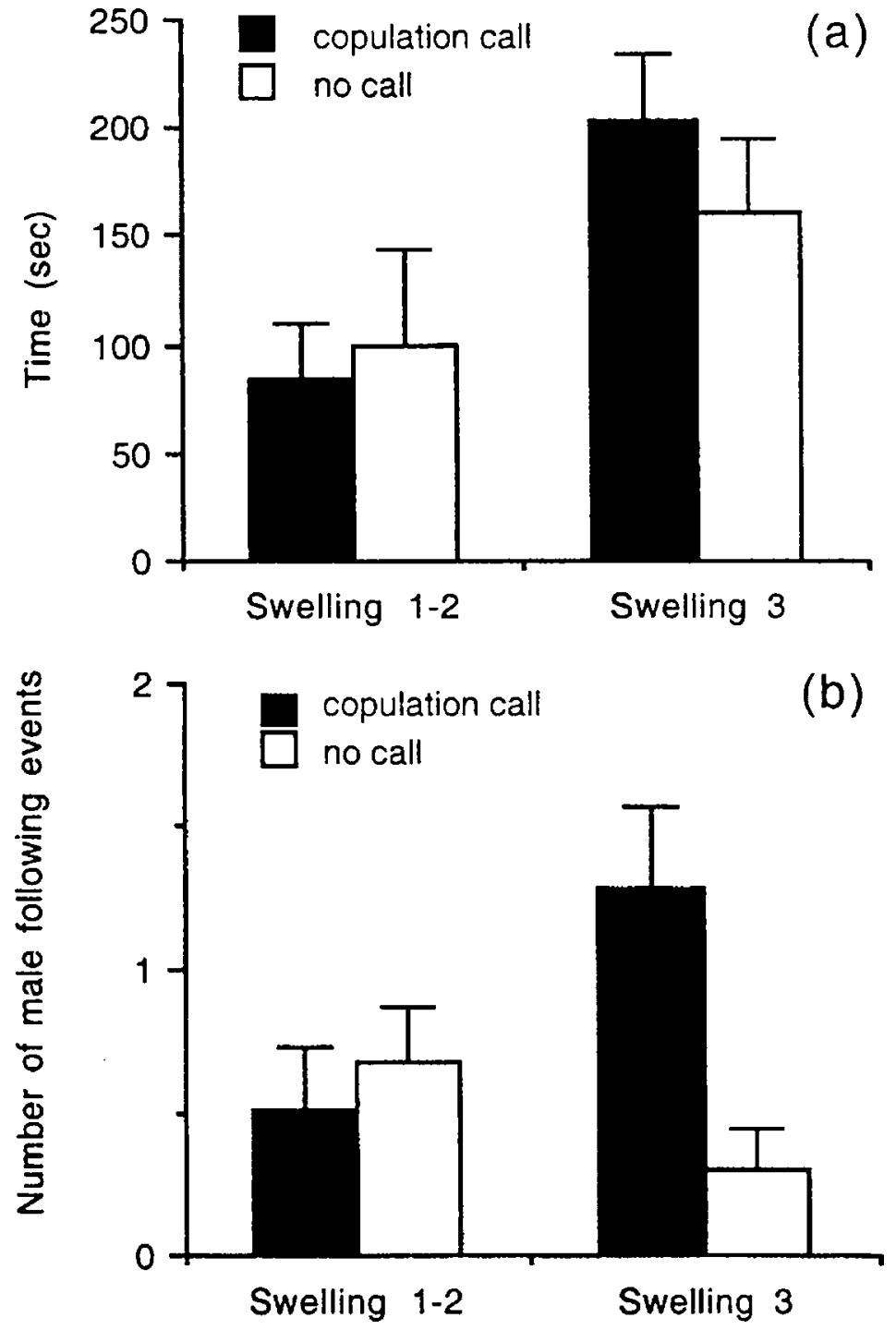

Fig. 6. (a). Mean $( \pm S E M)$ duration of proximity between the consort male and the consort female in the 10 -min copulatory period in relation to her sexual swelling size and the presence or absence of copulation calls. (b). Mean $( \pm \mathrm{SEM})$ number of times the consort male followed the consort female in the 10-min copulatory period in relation to her sexual swelling size and the presence or absence of copulation calls. (c). Mean ( \pm SEM) duration of maleinitiated proximity between the consort male and the consort female in the 10 -min copulatory period in relation to her sexual swelling size and the presence or absence of copulation calls. 


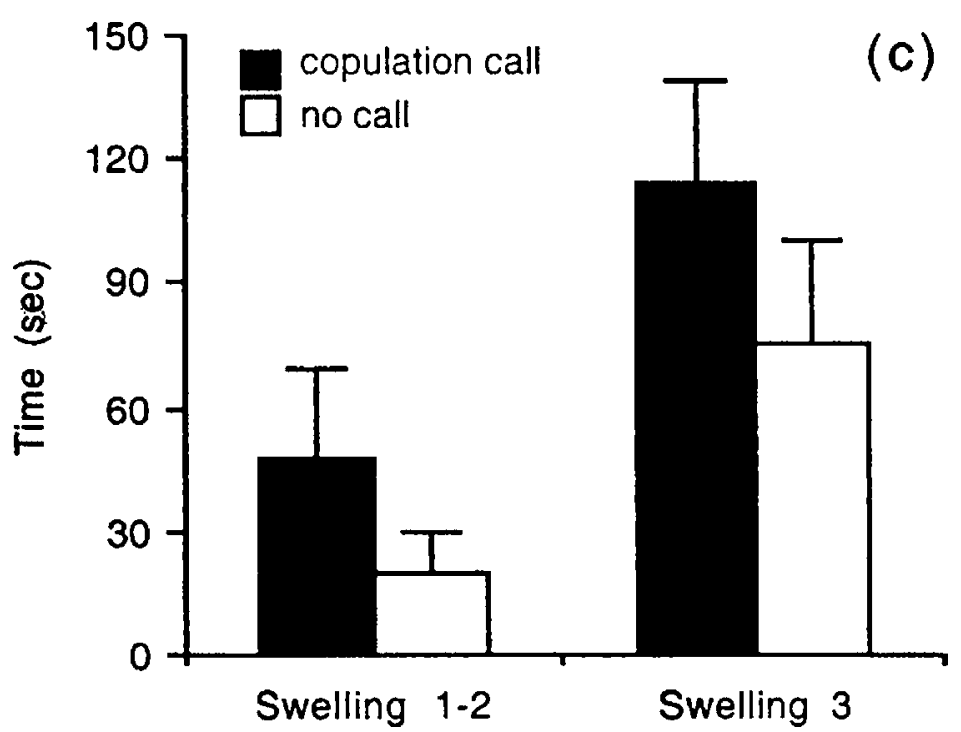

Fig. 6. continued

Observations ad libitum provided little evidence of any postcopulatory female sexual activity with nonconsort males within a few hours following copulation with the consort male. Although in many cases females copulated repeatedly with a particular male on the same day, in only one case did a female copulate with 2 different males on the same day, with an interval of about $3 \mathrm{~h}$ between them. Since we only observed the study group for 5-10 h per day, we cannot rule out that other copulations with consort or nonconsort males occurred after data collection was terminated.

\section{DISCUSSION}

This study is one of the first detailed accounts of copulatory activity in Guinea baboons, and it suggests that female copulation calls in primates may be a form of postcopulatory female choice.

The Guinea baboon males copulated with $\leq 5$ different females. Approximately two-thirds of the females copulated with only one male and one-third of them with 2 or 3 males. A study conducted with the same group, but different individuals, $>30$ yr ago showed a very similar pattern of copulatory activity (Boese, 1975). Together, the 2 studies suggest that, like hamadryas and gelada baboons (Stammbach, 1987), among Guinea baboons, small clusters of females mate with 1 or 2 males, perhaps a harem 
leader and a follower. This suggestion is also consistent with preliminary observations of Guinea baboons in the wild (Boese, 1975).

The copulating females were likely to have large sexual swellings and there was considerable variability in the amount of time spent in various swelling size stages by individual females. However, variation in the number of copulations is not accounted for by differences in the duration of swelling periods among females. We had no information on female dominance rank, but previous studies found no association between female dominance rank and size or duration of sexual swellings in baboons (Domb and Pagel, 2001). The only significant correlate of swelling period duration is the number of males with which the female mated. The females that copulated with 2 or 3 males had significantly higher daily average swelling size and significantly longer periods of time in full swelling than the females that copulated with one male did. Although it is difficult to establish a cause-effect relationship from the correlation, the finding is consistent with the suggestion that sexual swellings play an important role in mate attraction and male-male competition (Dixson, 1998; Nunn, 1999).

Variation in male copulatory success is accounted for by age and dominance rank. The younger and higher-ranking males were the most successful individuals. They performed more copulations, had more female partners, had a higher rate of copulation with their favorite partners, and there was also a tendency for high-ranking males to be most likely to copulate with fully swollen females. When $\geq 2$ males copulated with the same female, copulation rates were typically biased in favor of one male, though not always the higher-ranking one.

Approximately $60 \%$ of all copulations were accompanied by copulation calls. Previous research on baboons indicated considerable variation, both among different species and among different studies of the same species, in the percentage of copulations followed by calls (range: $10-98 \%$; Maestripieri and Roney, 2005). Across all females, copulation calls were likely to be associated with maximal sexual swelling. An intra subject analysis with a subset of individuals revealed no significant effect of swelling size on the probability of occurrence of copulation calls. However, the analysis included fewer than half the subjects because some females only copulated once and others only copulated in conjunction with maximal sexual swelling. In general, swelling size alone is not a strong predictor of variation in female copulation calls. Instead, the best predictors of copulation calls are the copulatory success of each female's primary copulating partner and the number of different males with which she copulated. Females that copulated mostly with highly successful males were the most likely to call after copulation, and females that copulated with 2 or 3 males were more likely to call than females that copulated with one male were. The findings 
are consistent with 2 key predictions of the female choice hypothesis: copulation calls express female preferences for particular males, and they are more likely to occur in conjunction with higher risk of sperm competition.

One could argue that the association between copulation calls and mating with multiple partners is also consistent with the sperm competition/paternity confusion hypothesis. This argument assumes that copulation calls are effective in stimulating mating with multiple partners, for which there is no clear empirical support, and that mate guarding by the consort male is ineffective. We argue instead that the sperm competition/paternity confusion hypothesis would predict a higher probability of copulation calls by females that mate with one or few males because of the greater need to encourage sperm competition or to confuse paternity under such conditions. Accordingly, the sperm competition/paternity confusion hypothesis is not supported by our findings.

The sperm-competition hypothesis would also predict that females should call especially after copulation with subordinate, subadult, or more generally, less successful males. The prediction is not supported by our study or by other previous research. Some previous studies indicated that copulation calls are more likely to occur with high-ranking than with lowranking males and with adult versus subadult males (Oda and Masakata, 1992; O'Connell and Cowlishaw, 1994; Saayman, 1970). In yellow baboons, calls given in conjunction with copulation with high-ranking males were also longer and contained more units (Semple et al., 2002). In the Brookfield Zoo subjects, male dominance rank and age were strong predictors of copulatory success, but male copulatory success was a better predictor of female copulation calls than either rank or age alone, which suggests that females are attracted to both high rank and young age combined. For example, it is possible that, at the proximate level, females give copulation calls because mating is stimulating and that higher-ranking and younger males provide more stimulation than other males. Alternatively, females may use high male copulation rates or other male behaviors associated with high copulation rates, e.g., aggressiveness or displays, to indicate male quality. Although some of these mechanisms of female mate choice have been reported in other species (Andersson, 1994), it is not clear whether they operate in primates (Paul, 2002). Another possibility is that females prefer males with compatible genotypes (Birkhead and Pizzari, 2002). Our findings suggest that different females had preferences for the same males, which argues against the genotype-compatibility hypothesis.

Further support for the female choice hypothesis of copulation calls was provided by the analyses of postcopulatory behavioral interactions. Male behavior in the 10-min postcopulatory period was affected by both the female's sexual swelling and her vocalizations. Copulating males were more 
likely to spend time in proximity to a female when she was fully swollen than when she was not, which suggests that female sexual swellings not only elicit sexual arousal in baboons (Bielert and Van der Walt, 1982; Girolami and Bielert, 1987) but also stimulate postcopulatory mate guarding (Nunn, 1999). Further, males were less likely to leave females when copulation was accompanied by a call than when it was not, regardless of the sexual swelling. This result is consistent with the findings of Todt et al. (1995) in Barbary macaques and suggests that copulation calls increase the probability of mate guarding, independently from the sexual swellings. Thus, it appears that both sexual swellings and copulation calls independently convey information about female fertility and the probability of conception. However, it is possible that while sexual swellings provide only a gross and inaccurate estimate of the time of ovulation (Nunn, 1999), copulation calls may provide a more precise predictor of ovulation and the probability of fertilization (Semple and McComb, 2000).

The female-choice hypothesis predicted that following copulation calls, the female should show no active interest in mating with other males, whereas the sperm competition/paternity confusion hypothesis predicted that following copulation calls, females should approach other males and actively solicit copulation from them. The lack of any significant difference in female behavior towards other males in relation to the presence or absence of copulation calls is consistent with the female-choice hypothesis and inconsistent with the sperm competition/paternity confusion hypothesis. Furthermore, there was little or no sexual activity between copulating females and other males within minutes or hours of a copulation episode.

The possible use of copulation calls to express postcopulatory female choice should be further investigated in baboons and other primate species. Postcopulatory female choice is expected to evolve in species in which females have little or no opportunity to express precopulatory mating preferences (Birkhead and Pizzari, 2002; Jones, 2002). In primates such as baboons and chimpanzees (Pan troglodytes), males are generally larger and more aggressive than females; therefore, there is potential for male coercion of mating (Smuts and Smuts, 1993). The use of copulation calls to express postcopulatory female choice would imply that even in species that are known for the brutality with which males control female behavior and coerce sexual activity, there may be subtle ways in which females can express their mating preferences and bias the probability of insemination in favor of males of their choice. It is also possible that female copulation calls have different functions in different primate species and while in some cases they express postcopulatory female choice, in others they encourage sperm competition. Further study of female copulation calls in baboons and other primates can enhance our understanding of the dynamics of mate 
competition and mate choice and make an important conceptual contribution to understanding the mechanisms of sexual selection.

\section{ACKNOWLEDGMENTS}

The study was supported by NIH grants R01-MH62577 and K02MH63097. We thank all the people at Brookfield Zoo who facilitated our data collection and Stuart Semple and Jim Roney for helpful comments and discussion. Part of the research was conducted by Marco Leoni to fulfil his M.A. requirements at the University of Chicago.

\section{REFERENCES}

Aich, H., Moos-Heilen, R., and Zimmerman, E. (1990). Vocalizations of adult gelada baboons (Theropitecus gelada): acoustic structure and behavioral context. Folia Primatol 55: 109132.

Anderson, J. R., and McGrew, W. C. (1984). Guinea baboons (Papio papio) at a sleeping site. Am. J. Primatol. 6: 1-14.

Andersson, M. (1994). Sexual Selection. Princeton University Press, Princeton, NJ.

Bercovitch, F. B. (1989). Body size, sperm competition, and determinants of reproductive success in male savanna baboons. Evolution 43: 1507-1521.

Bert, T., Ayats, H., Martino, A., and Collomb, H. (1967). Note sur l'organisation de la vigilance sociale chez le babouin Papio papio. Folia Primatol. 6: 44-47.

Bielert, C., and Van der Walt, L. A. (1982). Male chacma baboon (Papio ursinus) sexual arousal: mediation by visual cues from female conspecifics. Psychoneuroendocrinology 7: $31-48$.

Birkhead, T. R., and Pizzari, T. (2002). Postcopulatory sexual selection. Nature Rev. Genetics 3: $262-272$.

Boese, G. K. (1975). Social behavior and ecological considerations of West African baboons (Papio papio). In Tuttle, R. H. (ed.), Socioecology and Psychology of Primates. Mouton, The Hague, pp. 205-230.

Byrne, R. W. (1981). Distance vocalisations of Guinea baboons (Papio papio) in Senegal: An analysis of function. Behaviour 78: 283-313.

Cowlishaw, G., and O'Connell, S. M. (1996). Male-male competition, paternity certainty and copulation calls in female baboons. Anim. Behav. 51: 235-238.

Dixson, A. F. (1983). Observations on the evolution and behavioral significance of "sexual skin" in female primates. Adv. Study Behav. 13: 63-106.

Dixson, A. F. (1998). Primate Sexuality: Comparative Studies of the Prosimians, Monkeys, Apes, and Human Beings. Oxford University Press, Oxford.

Domb, L. G., and Pagel, M. (2001). Sexual swellings advertise female quality in wild baboons. Nature 410: 204-206.

Dunbar, R. I. M., and Dunbar, P. (1975). Social dynamics of gelada baboons. Contributions to Primatology, 6: 1-157. Karger, Basel.

Dunbar, R. I. M., and Nathan, M. F. (1972). Social organization of the Guinea baboon, Papio papio. Folia Primatol. 17: 321-334.

Gauthier, C. (1999). Reproductive parameters and paracallosal skin color changes in captive female Guinea baboons, Papio papio. Am. J. Primatol. 47: 67-74.

Girolami, L., and Bielert, C. (1987). Female perineal swelling and its effects on male sexual arousal: An apparent sexual releaser in the chacma baboon (Papio ursinus). Int. J. Primatol. 8: 651-661. 
Gomendio, M., Harcourt, A. H., and Roldan, E. R. S. (1998). Sperm competition in mammals. In Birkhead, T. R., and Moller, A. P. (eds.), Sperm Competition and Sexual Selection. Academic Press, San Diego: pp. 667-755.

Hamilton, W. J., and Arrowood, P. C. (1978). Copulatory vocalizations of chacma baboons (Papio ursinus), gibbons (Hylobates lar), and humans (Homo sapiens). Science 2001: 4051409.

Harcourt, A. H., Harvey, P. H., Larson, S. G., and Short, R. V. (1981). Testis weight, body weight, and breeding system in primates. Nature 293: 55-57.

Henzi, S. P. (1996). Copulation calls and paternity in chacma baboons. Anim. Behav. 51: 233234.

Jolly, C. J., and Phillips-Conroy, J. E. (2003). Testicular size, mating system, and maturation schedule in wild anubis and hamadryas baboons. Int. J. Primatol. 24: 125-142.

Jones, A. G. (2002). The evolution of alternative cryptic female choice strategies in agestructured populations. Evolution 56: 2530-2536.

Kummer, H. (1968). Social Organization of Hamadryas Baboons. University of Chicago Press, Chicago.

Maestripieri, D., and Roney, J. R. (2005). Primate copulation calls and post-copulatory female choice. Behavioral Ecology 16: 106-113.

Manson, J. H. (1997). Primate consortships. A critical review. Curr. Anthropol. 38: 353-374.

Melnick, D. J., and Pearl, M. C. (1987). Cercopithecines in multimale groups: genetic diversity and population structure. In Smuts, B. B., Cheney, D. L., Seyfarth, R. M., Wrangham, R. W., and Struhsaker, T. T. (eds.), Primate Societies. University of Chicago Press, Chicago, pp. 121-134.

Moos-Heilen, R., and Sossinka, R. (1990). The influence of oestrus on the vocalization of female gelada baboons (Theropithecus gelada). Ethology 84: 35-46.

Nunn, C. L. (1999). The evolution of exaggerated sexual swellings in primates and the gradedsignal hypothesis. Anim. Behav. 58: 229-246.

O'Connell, S. M., and Cowlishaw, G. (1994). Infanticide avoidance, sperm competition and mate choice: The function of copulation calls in female baboons. Anim. Behav. 48: 687694.

Oda, R., and Masataka, N. (1992). Functional significance of female Japanese macaque copulatory calls. Folia Primatol. 58: 146-149.

Paul, A. (2002). Sexual selection and mate choice. Int. J. Primatol. 23: 877-904.

Saayman, G. S. (1970). The menstrual cycle and sexual behaviour in a troop of free-ranging chacma baboons (Papio ursinus). Folia Primatol. 12: 81-110.

Semple, S. (1998). The function of Barbary macaque copulation calls. Proc. R. Soc. Lond. B 265: $287-291$.

Semple, S. (2001). Individuality and male discrimination of female copulation calls in the yellow baboon. Anim. Behav. 61: 1023-1028.

Semple, S., and McComb, K. (2000). Perception of female reproductive state from vocal cues in a mammal species. Proc. R. Soc. Lond. B 264: 707-712.

Semple, S., McComb, K., Alberts, S., and Altmann, J. (2002). Information content of copulation calls in yellow baboons. Am. J. Primatol. 56: 43-56.

Shaik, A. A., Celaya, C. L., Gomez, I., and Shaikh, S. A. (1982). Temporal relationship of hormonal peaks to ovulation and sex skin deturgescence. Primates 23: 444-452.

Smuts, B. B., and Smuts, R. W. (1993). Male aggression and sexual coercion of females in nonhuman primates and other mammals: Evidence and theoretical implications. Adv. Study Behav. 22: 1-63.

Stammbach, E. (1987). Desert, forest, and montane baboons: Multilevel societies. In Smuts, B. B., Cheney, D. L., Seyfarth, R. M., Wrangham, R. W., and Struhsaker, T. T. (eds.), Primate Societies. University of Chicago Press, Chicago, pp. 112-120.

Swedell, L., and Saunders, J. (2003). Female reproductive strategies in hamadryas baboons: paternity certainty, infanticide avoidance, and copulation calls.-Paper presented at the Annual Meeting of the American Association for Physical Anthropology, Tempe, AZ. 
Todt, D., Hammerschmidt, K., Ansorge, V., and Fischer, J. (1995). The vocal behavior of Barbary macaques (Macaca sylvanus): Call features and their performance in infants and adults. In Zimmermann, E., Newman, J. D., and Jurgens, U. (eds.), Current Topics in Primate Vocal Communication. Plenum Press, New York, pp. 141-160.

Zinner, D., and Deschner, T. (2000). Sexual swellings in female hamadryas baboons after male take-overs: "Deceptive" swellings as a possible female counter-strategy against infanticide. Am. J. Primatol. 52: 157-168. 